\title{
Retroactive effects in S1-R2 and S2-R1 paradigms'
}

JOHN P. HOUSTON

UNIVERSITY OF CALIFORNIA, LOS ANGELES

A preliminary study was conducted to indicate whether two transfer surfaces described by Houston (1964; 1965) would be useful in predicting retroactive effects. First-list retention was measured in five two-list paradigms (A-B, B-A; A-B, C-A; $\left.A-B, C-D ; A-B, B-C ; A-B, B-A_{r}\right)$ and a single-list control condition. With one major exception the pattern of the results conformed to the predictions of the surface. The exception was the A-B, C-A paradigm which produced much poorer firstlist recall than that predicted by the surfaces. While not overwhelmingly convincing, these data suggest that the surfaces may contain some accurate predictions conceming retroactive effects.

Two surfaces described by Houston $(1964,1965)$ relate degree and direction of transfer to the similarity between first-list stimuli and second-list responses (S1-R2) and to the similarity between second-list stimuli and first-list responses (S2-R1). Some, although not all, of the transfer relationships have been experimentally demonstrated (Houston, 1966a, b, c). While the two surfaces were designed to summarize transfer effects there is the possibility that they may be useful, as is true of Osgood's (1949) surface, in predicting retroactive effects. The present preliminary study was designed to indicate whether this use of the surfaces is at all feasible. First-list recall was measured in five two-list paradigms taken from the two surfaces (A-B, B-A; A-B, C-A; A-B, C-D; A-B, B-C; A-B, B-A ). A control group learned and recalled a single list. While the rationale for these predictions will not be detailed, the amounts of firstlist recall predicted by the surfaces are as follows. Recall in the A-B, B-A paradigm should be best, followed by the single-list control condition. Next, the $A-B, C-A$ and $A-B, C-D$ paradigms should produce about equal recall. The $A-B, B-C$ paradigm, a negative transfer paradigm, should produce the next best recall. The $\mathrm{A}-\mathrm{B}, \mathrm{B}-\mathrm{A}_{\mathrm{r}}$ paradigm, in which the first-list stimuli are repaired with the $B$ units in the second list, should produce the poorest recall.

\section{Method}

The six conditions were randomized 16 times such that each occurred once in each succeeding block of six conditions. The $96 \mathrm{Ss}$, University of California undergraduates, were assigned to this arrangement as they appeared in the testing situation. Ss in the five experimental conditions learned two successive eight-item paired-associate lists. The control Ss learned a single list and then worked a pyramid puzzle for a time equivalent to that required by the two-list Ss to learn the second list. Both lists were composed of common adjectives. taken from Haagen's (1949) norms. All $\mathrm{Ss}$ learned the same first-list. Five different second-lists were constructed to correspond to one of the five paradigms. All the words within each of the stimulus and response sets began with different letters. The stimulus and response members of all pairs began with different letters. Four different presentations orders of each list were constructed and each was used equally frequently as the starting order. All learning was conducted at a 2:2 sec. rate on a Stowe drum with 4 sec. intertrial and $45 \mathrm{sec}$. interlist intervals. First-list learning was taken to a criterion of one perfect trial while second-list learning was carried for 15 anticipation trials. Firstlist retention was tested 45 sec. after the completion of the second task. Ss were given a sheet of paper with each of the stimuli followed by a blank space and were allowed as much time as they wished to recall the correct responses and to record them in the appropriate spaces. If it is assumed that this type of recall task eliminates competition at the time of recall then the obtained results may be attributed to the unleaming factor alone.

\section{Results and Discussion}

Table 1 contains the mean numbers of first-list trials to criterion, the mean numbers of correct second-list responses, and the mean first-list recall values for the six conditions. No significant differences appeared among the six first-list learning means, $F<1, d f=5 / 90$. An analysis of variance indicated that there were significant differences among the five second-list means, $F=13.16$, df $=4 / 75, p<.01$. These second-list data conform to the overall transfer predictions summarized by the two surfaces. That is, relative to the A-B, C-D control, second-list learn-

Table 1. First-list, second-list and recall data means

\begin{tabular}{|c|c|c|c|c|c|c|}
\hline & \multicolumn{6}{|c|}{ Paradigm } \\
\hline & $\begin{array}{l}\text { A-B } \\
\text { B-A }\end{array}$ & $\begin{array}{l}A-B \\
--\end{array}$ & $\begin{array}{l}\text { A-B } \\
\text { C-D }\end{array}$ & $\begin{array}{l}\text { A-B } \\
\text { C-A }\end{array}$ & $\begin{array}{l}\text { A-B } \\
\text { B-C }\end{array}$ & $\begin{array}{l}A-B \\
B-A_{r}\end{array}$ \\
\hline $\begin{array}{l}\text { First-list trials } \\
\text { to criterion }\end{array}$ & 10.31 & 10.94 & 9.13 & 12.44 & 8.94 & 10.69 \\
\hline $\begin{array}{l}\text { Correct second- } \\
\text { list responses }\end{array}$ & 112.25 & $=-$ & 94.88 & 91.38 & 83.50 & 70.31 \\
\hline $\begin{array}{l}\text { Correct first- } \\
\text { list recall }\end{array}$ & 7.94 & 7.63 & 6.81 & 4.38 & 6.44 & 5.81 \\
\hline
\end{tabular}


ing was quite easy in the A-B, B-A conditions, about the same in the A-B, C-A paradigm, somewhat more difficult in the A-B, B-C paradigm, and most difficult in the $A-B, B-A_{r}$ situation. Of course, these transfer data can only be suggestive as this experiment did not include appropriate transfer controls. Analysis of variance indicated significant differences among the six recall means, $F=10.58$, df $=5 / 90, p<.01$. The recall predictions, with one major exception, tended to be confirmed. That is, with the exception of the $A-B, C-A$ paradigm, the means arranged themselves in the predicted order. Recall in the A-B, C-A situation was much poorer than that predicted by the surfaces. Additional statistical comparisons were not attempted with these preliminary data. Further data should be gathered before anything more than a suggestive statement is made concerning the usefulness of these surfaces in predicting retroactive effects.

\section{References}

Haagen, C. H. Synonymity, vividness, familiarity, and associativevalue ratings of 400 pairs of common adjectives. J. Psychol., $1949,30,185-200$.

Houston, J. P. Verbal transfer and interlist similarities. Psychol. Rev., 1964, 71, 412-414.

Houston, J. P. A repaired S1-R2, and S2-R1 transfer surface. Psychon. Sci., 1965, 3, 343-344.

Houston, J. P. Supplementary report: Transfer as a function of the similarity between first-list stimuli and second-list responses. $J$. verbal Learn. verbal Behav., 1966a, 5, 322-323.

Houston, J. P. Transfer in repaired S1-R2 and S2-R1 paradigms. Psychon. Sci., 1966b, 4, 83-84.

Houston, J. P. Verbal transfer as a function of S1-R2 and S2-R1. J. exp. Psychol., 1966c, 71, 232-235.

Osgood, C. E. The similarity paradox in human learning: A resolution. Psychol. Rev., 1949, 56, 132-143.

\section{Note}

1. This work was supported by a grant (MH 11199-02) from the National Institute of Mental Health, Public Health Service. 